International Mathematical Forum, Vol. 9, 2014, no. 18, 891 - 906 HIKARI Ltd, www.m-hikari.com http://dx.doi.org/10.12988/imf.2014.4459

\title{
Geometric Demonstration of the Generalized Unique Intervallic Multiplicity Theorem
}

\author{
Brian J. M뜨artin \\ Applied Mathematics, Kettering University \\ 1700 University Avenue, Flint, MI 48504-6214 USA
}

Copyright (C) 2014 Brian J. M들. Cartin. This is an open access article distributed under the Creative Commons Attribution License, which permits unrestricted use, distribution, and reproduction in any medium, provided the original work is properly cited.

\begin{abstract}
A geometric approach is developed to prove that, up to rotation, reflection and circle-of-fifths transformation, the diatonic hexachord and septachord are the only musical scales possessing the Generalized Unique Intervallic Multiplicity Property.
\end{abstract}

\section{Prelude}

The present paper is intended as a sequel to [5] wherein was provided a geometric demonstration of the Unique Intervallic Multiplicity Theorem which states that, up to rotation, reflection and circle-of-fifths transformation, only the diatonic septachord possesses the Unique Intervallic Multiplicity (UIM) Property [6, p. 100]. Herein is provided a corresponding geometric demonstration of the Generalized Unique Intervallic Multiplicity Theorem which states that, up to rotation, reflection and circle-of-fifths transformation, only the diatonic hexachord and septachord possess the Generalized Unique Intervallic Multiplicity (GUIM) Property [7, p. 11 \& p. 62].

In the ensuing development,the concept of prime form [7, p. 42] of a pitchclass (pc) set is introduced and a basic result thereto appertaining is stated and proved. This is followed by a review of Unique Intervallic Multiplicity (UIM) together with the associated septachord intervallic bounds established in its corresponding proof [5]. Finally, Generalized Unique Intervallic Multiplicity (GUIM) receives thorough treatment. (See my Prelude to Musical Geometry [4] for all mathemusical terminology.) 


\section{Prime Form}
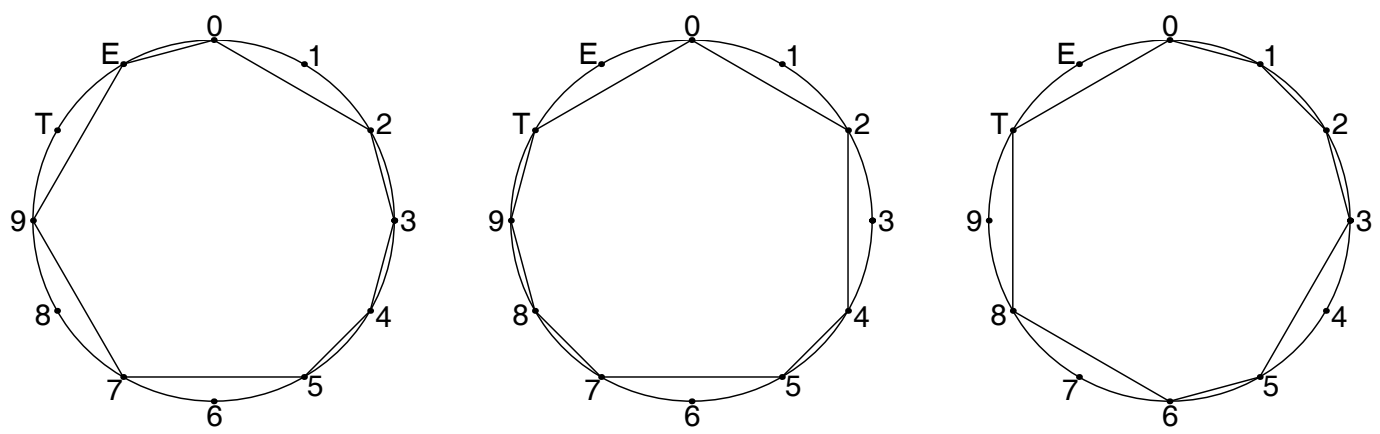

Figure 1: Prime Form

The mathematical model of pitch adopted forthwith identifies a pitch-class (pc) set with any of its transpositions or inversions. Such an equivalence class of pc-sets is called a set class [7, p. 39]. For each such set class, it is desirable to have a canonical representative. This is provided by the concept of prime form [7, p. 41] as described in the following geometric-algorithmic definition. (This prime form is usually described as "beginning with 0 and most packed to the left" (read clockwise) [7, p. 42].)

Definition 1 (Prime Form) The prime form of the set class containing the pc-set corresponding to the pc-polygon $\mathcal{P}$ [4] is obtained as follows:

1. Make a list of the edges of greatest length of $\partial \mathcal{P}$ and, for each such largest edge, choose the direction, clockwise or counterclockwise, with the adjacent edge of greatest length. If both adjacent edges have equal length then choose both directions.

2. For each such ordered pair (largest edge, direction), begin at the corresponding largest edge and proceed edge-by-edge in the chosen direction, all the time comparing the length of each new edge with those of all remaining competing ordered pairs while eliminating any such ordered pairs which are inferior in the sense of encountering a smaller edge.

3. Continue this edge-by-edge competition until either there is only one remaining competitor or $\partial \mathcal{P}$ has been circumnavigated.

4. Using any surviving ordered pair, rotate $\mathcal{P}$ in the clockwise direction until the corresponding largest edge of $\partial \mathcal{P}$ first encounters 0.

5. If the corresponding direction is clockwise then reflect $\mathcal{P}$ about the perpendicular bisector of this largest edge. 
6. The pc-set corresponding to this rotated/reflected pc-polygon is the prime form of the pc-set corresponding to $\mathcal{P}$ or, alternatively, the prime form of the associated set class.
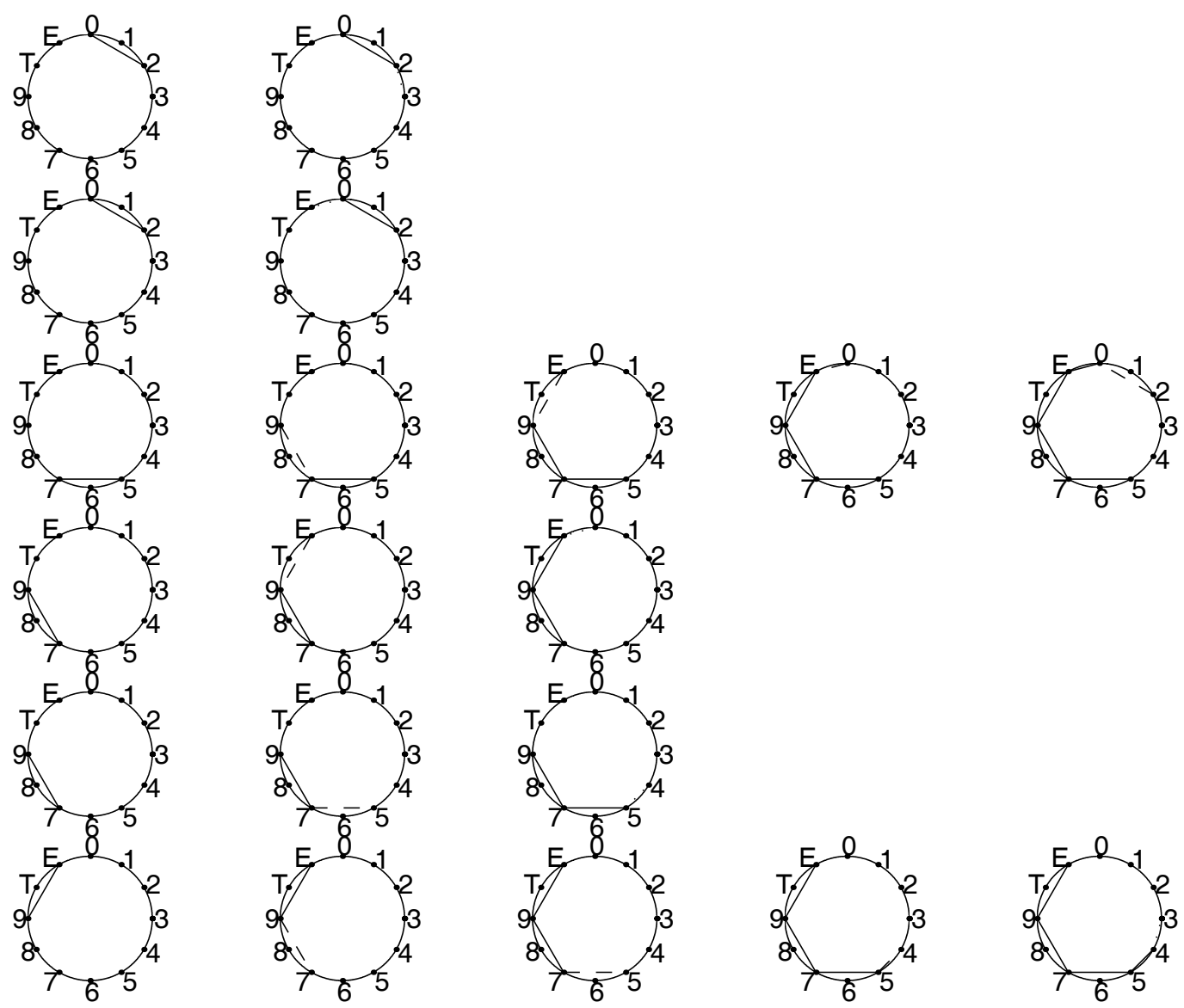

Figure 2: Geometric Algorithm

As an illustrative example, consider the octachord $[0,2,3,4,5,7,9, E]$ as shown in the left frame of Figure 1. Steps 1 through 3 of the geometric algorithm of Definition 1 are on display in Figure 2 (each row corresponds to an ordered pair and each column corresponds to a round of the competition) and reveal that $(5-7, c w)$ is the sole remaining ordered pair ("successful" edges allowing an ordered pair to continue in the competition are dashed while "unsuccessful" edges resulting in the elimination of an ordered pair are dotted). In accordance with Step 4, the left frame of Figure 1 is then rotated clockwise into $[0,2,4,5,7,8,9, T]$ thereby producing the center frame. Finally, the right frame of Figure 1 containing the prime form $[0,1,2,3,5,6,8, T]$ is obtained from the center frame via the reflection described in Step 5. 

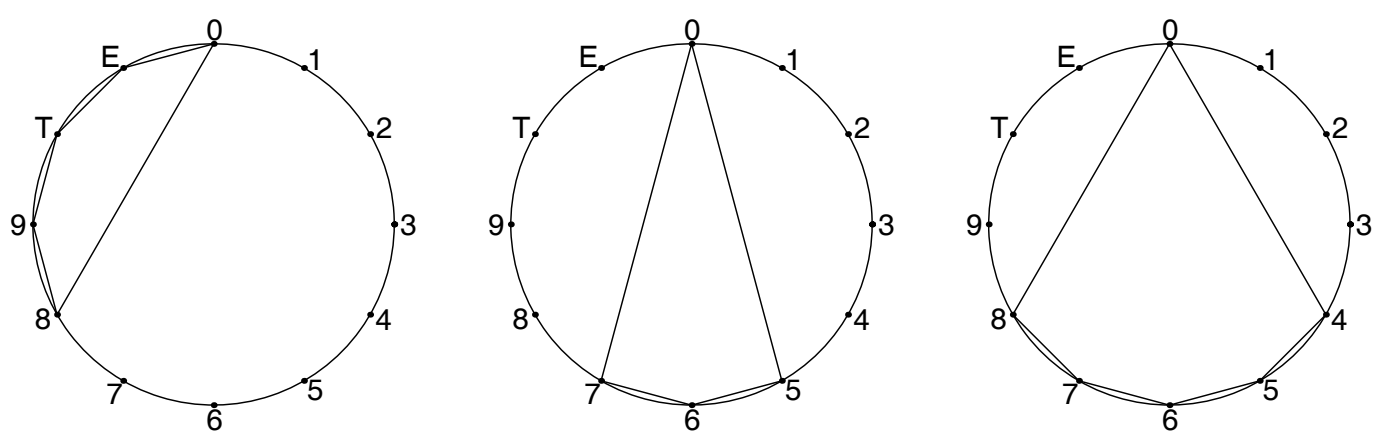

Figure 3: Hexachordal Prime Forms (1)

The geometric proof of the GUIM Theorem that will provide the climax to the present investigation will lean heavily upon the following important result concerning hexachordal prime forms.

Theorem 1 (Hexachordal Prime Forms) All hexachords in prime form must open with one of the following five triadic patterns:

- $[0,1,2, \cdot, \cdot, \cdot]$

- $[0,1,3, \cdot, \cdot, \cdot]$

- $[0,1,4, \cdot, \cdot, \cdot]$

- $[0,2,3, \cdot, \cdot, \cdot]$

- $[0,2,4, \cdot, \cdot, \cdot]$

Proof:

- A hexachord cannot open with $[0,8, \cdot, \cdot, \cdot, \cdot \cdot]$ thru $[0,11, \cdot, \cdot, \cdot, \cdot]$ since that would not leave sufficiently many pitches to form a hexachord. (See Figure 3, Left.)

- A hexachord in prime form cannot open with $[0,5, \cdot, \cdot, \cdot, \cdot]$ thru $[0,7, \cdot, \cdot, \cdot, \cdot]$ since that would not leave sufficiently many pitches to form a hexachord. (See Figure 3, Center.)

- A hexachord in prime form which opens with $[0,4, \cdot, \cdot, \cdot, \cdot]$ must, by necessity, be $[0,4,5,6,7,8]$ since prime form requires that the last interval-class (read clockwise from 0) must be the largest. However, this hexachord has prime form $[0,1,2,3,4,8]$. (See Figure 3, Right.) 

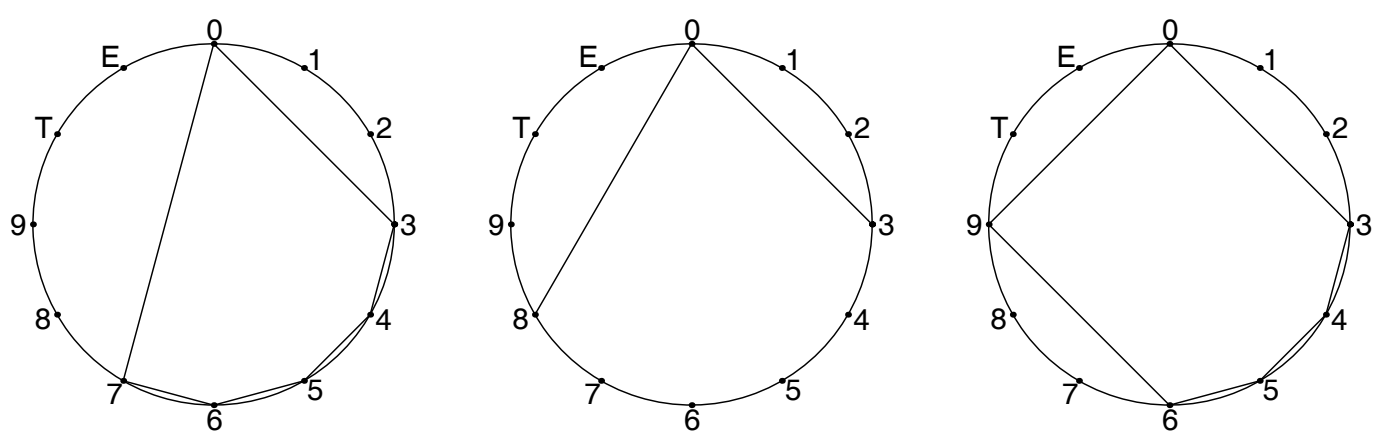

Figure 4: Hexachordal Prime Forms (2)

- A hexachord in prime form cannot open with $[0,3, \cdot, \cdot, \cdot, \cdot]$ because its last interval-class would then have to be ic-3, ic-4 or ic-5, since a smaller interval-class would violate the definition of prime form while a larger interval-class would not leave enough remaining pitches to accommodate a hexachord. However, none of these choices for last interval-class would lead to prime form. This is most easily seen by inspection of Figure 4.

- In the left frame, a final interval-class of ic-5 automatically leads to the hexachord $[0,3,4,5,6,7]$ whose prime form $[0,1,2,3,4,7]$ is obtained via the reflection $T_{7} I$.

- In the center frame, a final interval-class of ic-4 implies that, so as to accommodate a hexachord, the remaining interval-classes all be either ic- 2 or ic- 1 in which case prime form is achieved via the reflection $T_{8} I$.

- In the right frame, a choice of final and penultimate interval-classes of ic-3 automatically leads to the hexachord $[0,3,4,5,6,9]$ whose prime form $[0,1,2,3,6,9]$ is obtained via the rotation $T_{-3}$. Replacement of the edge $6-9$ by a smaller one cannot produce prime form since the rotation $T_{-3}$ then clearly produces a chord closer to prime form ("more packed to the left").

- A hexachord in prime form commencing with the dyad $[0,2, \cdot, \cdot, \cdot, \cdot]$ must open with one of the following triadic patterns: $[0,2,3, \cdot, \cdot, \cdot]$ or $[0,2,4, \cdot, \cdot, \cdot]$.

- A hexachord cannot open with $[0,2,9, \cdot, \cdot, \cdot]$ thru $[0,2,11, \cdot, \cdot, \cdot]$ since that would not leave sufficiently many pitches to form a hexachord.

- A hexachord in prime form cannot open with $[0,2,6, \cdot, \cdot, \cdot]$ thru $[0,2,8, \cdot, \cdot, \cdot]$ since that would not leave sufficiently many pitches to form a hexachord. 

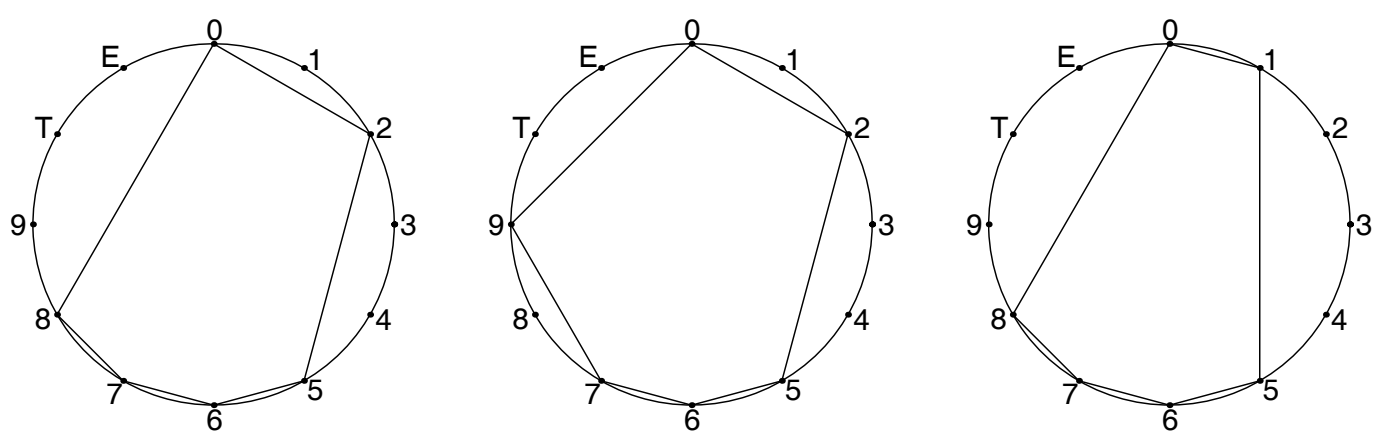

Figure 5: Hexachordal Prime Forms (3)

- A hexachord in prime form which opens with $[0,2,5, \cdot, \cdot, \cdot]$ must be either $[0,2,5,6,7,8]$ with prime form $[0,1,2,3,6,8]$ (see Figure 5, Left) or $[0,2,5,6,7,9]$ with prime form $[0,1,2,4,7,9]$ (see Figure 5, Center).

- A hexachord in prime form commencing with the dyad $[0,1, \cdot, \cdot, \cdot, \cdot]$ must open with one of the following triadic patterns: $[0,1,2, \cdot, \cdot, \cdot],[0,1,3, \cdot, \cdot, \cdot]$ or $[0,1,4, \cdot, \cdot, \cdot]$.

- A hexachord cannot open with $[0,1,9, \cdot, \cdot, \cdot]$ thru $[0,1,11, \cdot, \cdot, \cdot]$ since that would not leave sufficiently many pitches to form a hexachord.

- A hexachord in prime form cannot open with $[0,1,6, \cdot, \cdot, \cdot]$ thru $[0,1,8, \cdot, \cdot, \cdot]$ since that would not leave sufficiently many pitches to form a hexachord.

- A hexachord in prime form which opens with $[0,1,5, \cdot, \cdot, \cdot]$ must be $[0,1,5,6,7,8]$ with prime form $[0,1,2,3,7,8]$ (see Figure 5 , Right).

\section{Unique Intervallic Multiplicity}

The prime form of the diatonic septachord $[0,1,3,5,6,8, T]$ with interval vector $\langle 2,5,4,3,6,1\rangle$ is shown in the left frame of Figure 6 while the prime form of the chromatic septachord $[0,1,2,3,4,5,6]$ with interval vector $\langle 6,5,4,3,2,1\rangle$ is shown in the right frame of Figure 6 . These two chords are images of one another under the circle-of-fifths transformation of Figure 7. Note that, in both cases, each interval-class (ic) appears a unique number of times. 

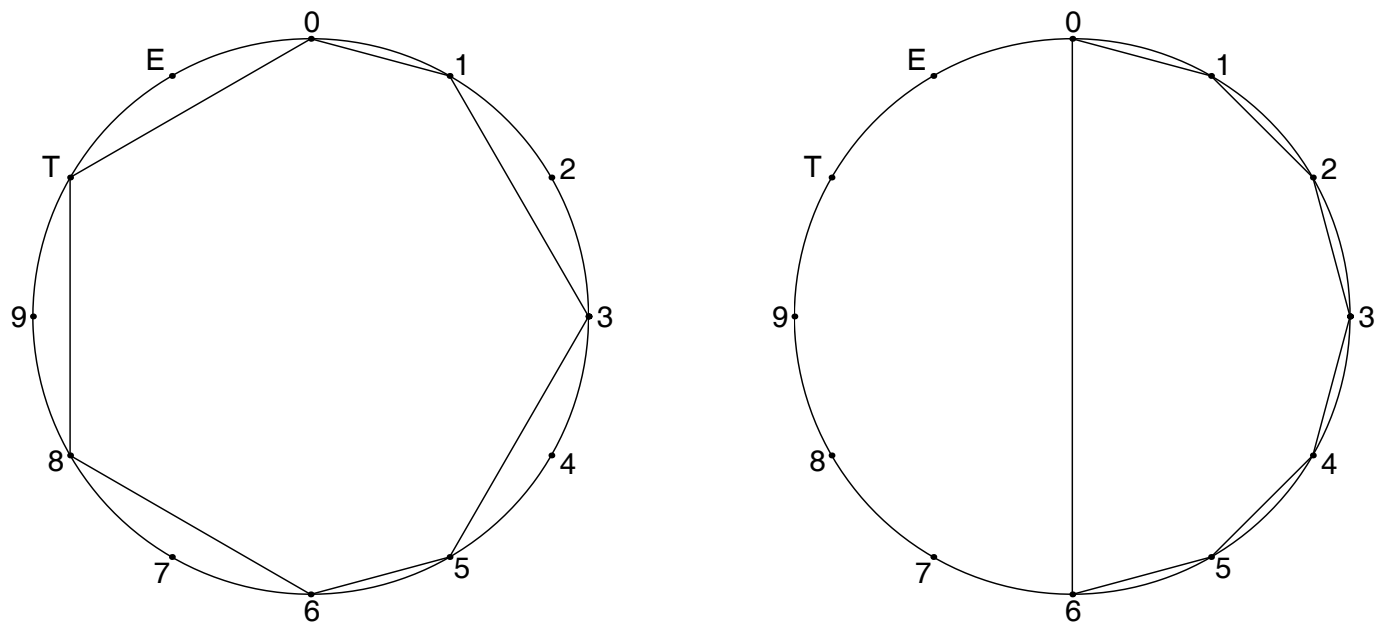

Figure 6: Diatonic and Chromatic Septachords

Definition 2 (Unique Intervallic Multiplicity Property) Any pitch-class (pc) set whose interval vector contains distinct positive entries is said to possess the Unique Intervallic Multiplicity (UIM) Property.

In point of fact, the only chords, up to rotation and reflection, possessing the UIM Property are those shown in Figure 6. This is the content of the UIM Theorem which was proved geometrically in [5].

Theorem 2 (Unique Intervallic Multiplicity) Up to rotation, reflection and circle-of-fifths transformation, only the diatonic septachord possesses the Unique Intervallic Multiplicity Property.

The following theorem, which will be useful in the next section, was also proved in [5].

Theorem 3 (Septachord Intervallic Bounds) Any septachord must contain a least one of each interval-class. More specifically, the range of values for the components of the interval vector of any septachord are given by $\langle 2-6,2-6,2-6,3-6,2-6,1-3\rangle$.

\section{Generalized Unique Intervallic Multiplicity}

The prime form of the diatonic hexachord $[0,2,4,5,7,9]$ with interval vector $\langle 1,4,3,2,5,0\rangle$ is shown in the left frame of Figure 8 while the prime form of the chromatic hexachord $[0,1,2,3,4,5]$ with interval vector $\langle 5,4,3,2,1,0\rangle$ is shown in the right frame of Figure 8. These two chords are images of one 


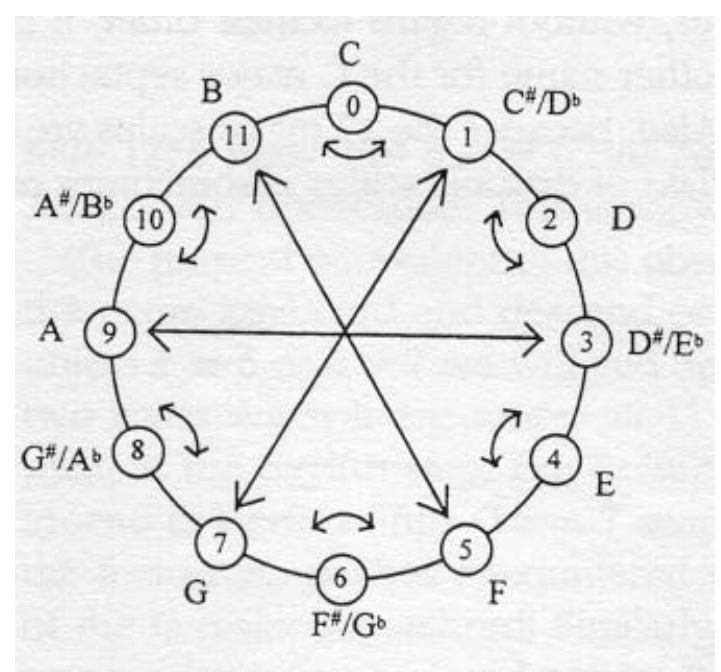

Figure 7: Circle-of-Fifths Transform $M_{7}$

another under the circle-of-fifths transformation of Figure 7. Note that, in both cases, each interval-class (ic) appears a unique number of times. Relaxing the restriction that entries in the interval vector must be nonzero results in a generalization of the UIM Property.

\section{Definition 3 (Generalized Unique Intervallic Multiplicity Property)} Any pitch-class (pc) set whose interval vector contains distinct nonnegative entries is said to possess the Generalized Unique Intervallic Multiplicity (GUIM) Property.

In point of fact, the only chords, up to rotation and reflection, possessing the GUIM Property are those on display in Figures $6 \&$ 8. This is the content of the GUIM Theorem which will be proved geometrically at the conclusion of this paper. However, some preliminary results must first be developed.

Theorem 4 Any chord possessing the GUIM Property but not possessing the UIM Property is necessarily a hexachord.

Proof: By Theorem 3, any septachord satisfies the intervallic lower bounds $\langle\geq 2, \geq 2, \geq 2, \geq 3, \geq 2, \geq 1\rangle$ so that any chord of higher cardinality (i.e. octachord, nonachord, decachord, undecachord or dodecachord) must also satisfy these inequalites (although they are no longer necessarily tight). Since a chord possessing the GUIM Property but not possessing the UIM Property must contain a 0 in its interval vector, these lower bounds imply that any such chord may have cardinality at most 6 . However, the smallest possible sum for the 

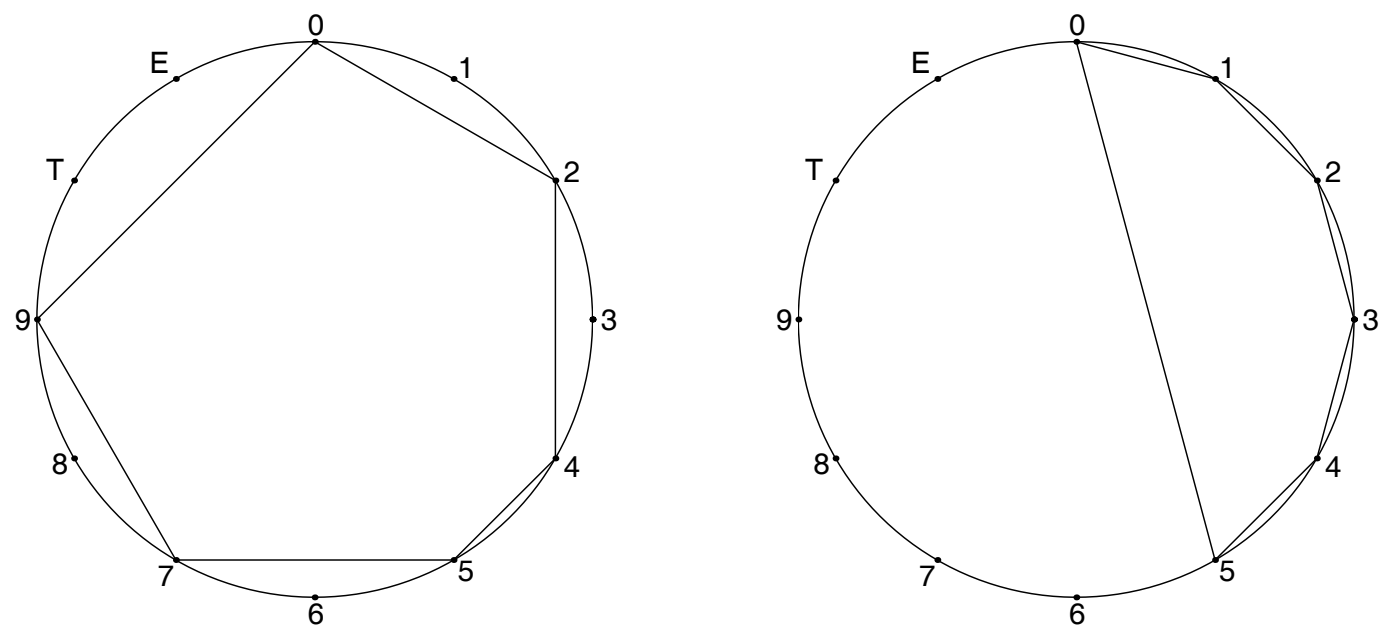

Figure 8: Diatonic and Chromatic Hexachords

remaining nonzero entries of the interval vector is $1+2+3+4+5=15$. Since the sum of the elements of the interval vector of a chord of cardinality $n$ is equal to $\frac{n(n-1)}{2}$, this implies that $n \geq 6$. Combined with our prior observation that $n \leq 6$, we arrive at the conclusion that $n=6$.

Theorem 5 If a hexachord possesses the GUIM Property then its interval vector must be comprised of a permutation of $\{0,1,2,3,4,5\}$

Proof: As shown in [5], only a septachord may have the UIM Property so that if a hexachord has the GUIM Property then it must contain a 0 in its interval vector. Since the remaining nonzero elements of the interval vector must sum to 15 for any hexachord and the only five distinct nonzero integers summing to 15 are $\{1,2,3,4,5\}$, we may conclude that its interval vector must be comprised of a permutation of $\{0,1,2,3,4,5\}$.

Corollary 1 Any hexachord possessing the GUIM Property must exclude exactly one interval-class.

Proof: This follows directly from the fact that the interval vector of a hexachord possessing the GUIM Property must contain exactly one 0.

Theorem 6 (Generalized Unique Intervallic Multiplicity) Up to rotation, reflection and circle-of-fifths transformation, only the diatonic hexachord and the diatonic septachord possess the Generalized Unique Intervallic Multiplicity Property. 

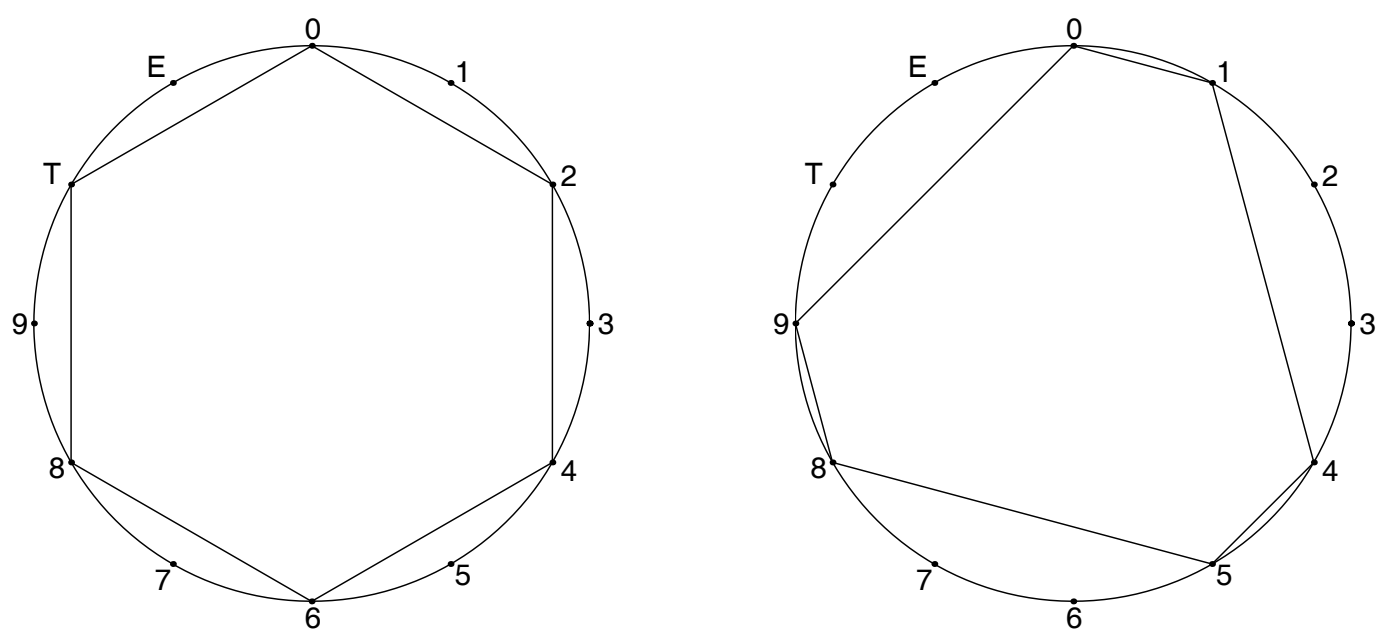

Figure 9: Excluding Minor and Major Seconds

Proof: Corollary 1 suggests a strategy for proving the GUIM Theorem. Specifically, hexachords that exclude each interval-class, in turn, will be considered.

- ic-1: The only opening triadic pattern of a hexachord in prime form which excludes ic-1 is $[0,2,4, \cdot, \cdot, \cdot]$. Since this is equivalent to excluding adjacent pitch-classes of the musical clock, the only possible such hexachord, shown in the left frame of Figure 9, is $[0,2,4,6,8, T]$ whose interval vector is $\langle 0,6,0,6,0,3\rangle$. This clearly does not possess the GUIM Property.

- $\underline{\text { ic-2: }}$ The only opening triadic pattern of a hexachord in prime form which excludes ic-2 is $[0,1,4, \cdot, \cdot, \cdot]$. This automatically excludes pitch-classes $2,3,6, T, E$. The final pitch-class, reading clockwise from 0 , must be 9 since choosing 8 would also force the inclusion of edge $5-7$ which forms ic-2 which must be excluded, while choosing an interval-class smaller than 8 would not allow the accommodation of a hexachord. Thus, we are ultimately led to the only possible such hexachord, shown in the right frame of Figure 9, which is $[0,1,4,5,8,9]$ whose interval vector is $\langle 3,0,3,6,3,0\rangle$. This clearly does not possess the GUIM Property.

- ic-3: The only opening triadic patterns of a hexachord in prime form which exclude ic-3 are $[0,1,2, \cdot, \cdot, \cdot]$ and $[0,2,4, \cdot, \cdot, \cdot]$.

- $[0,1,2, \cdot, \cdot, \cdot]:$ This automatically excludes pitch-classes $3,4,5,9, T, E$ leaving only pitch-classes $6,7,8$ to complete the hexachord. Thus, we are immediately led to the only possible such hexachord, shown in the left frame of Figure 10 , which is $[0,1,2,6,7,8]$ whose interval 

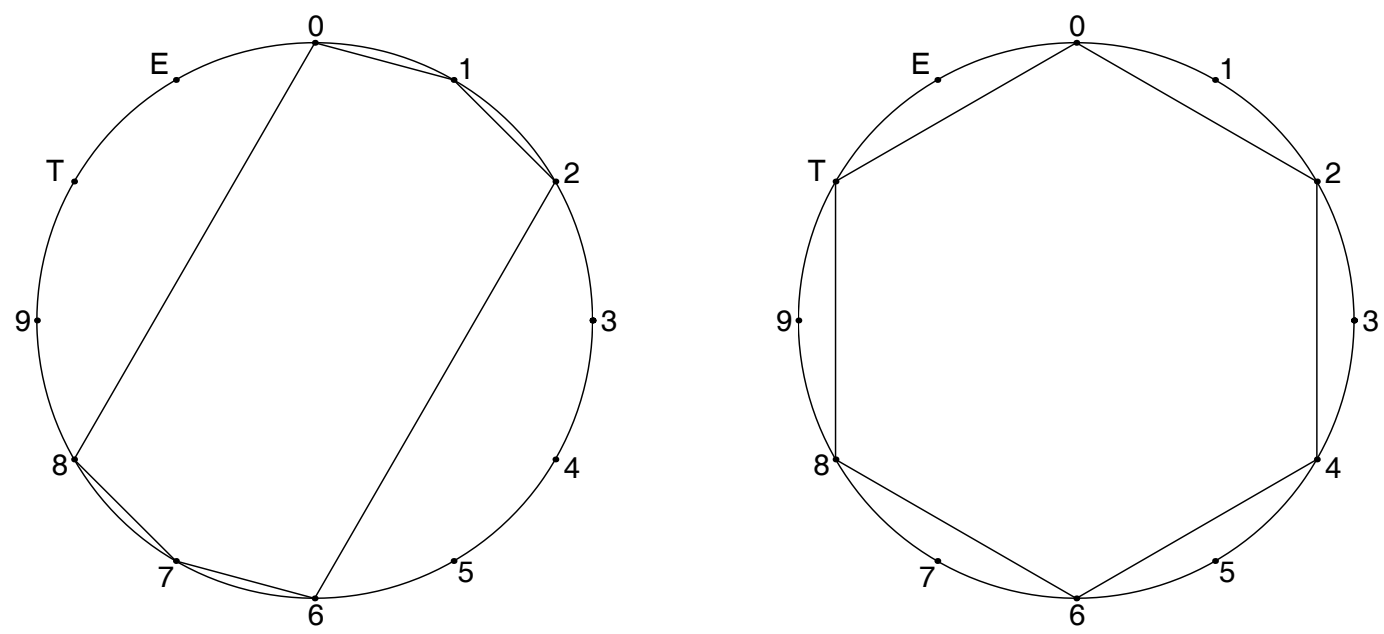

Figure 10: Excluding Minor Thirds

vector is $\langle 4,2,0,2,4,3\rangle$. This clearly does not possess the GUIM Property.

- $[0,2,4, \cdot, \cdot, \cdot]:$ This automatically excludes pitch-classes $1,3,5,7,9, E$ leaving only pitch-classes $6,8, T$ to complete the hexachord. Thus, we are immediately led to the only possible such hexachord, shown in the right frame of Figure 10, which is $[0,2,4,6,8, T]$ whose interval vector is $\langle 0,6,0,6,0,3\rangle$. This clearly does not possess the GUIM Property.

- $\underline{\text { ic-4: }}$ : The only opening triadic patterns of a hexachord in prime form which exclude ic-4 are $[0,1,2, \cdot, \cdot, \cdot],[0,1,3, \cdot, \cdot, \cdot]$ and $[0,2,3, \cdot, \cdot, \cdot]$.

- $[0,1,2, \cdot, \cdot, \cdot]:$ This automatically excludes pitch-classes $4,5,6,8,9, T$ leaving only pitch-classes $3,7, E$ to complete the hexachord. Thus, we are immediately led to the hexachord $[0,1,2,3,7, E]$, shown in the left frame of Figure 11, which not only fails to be in prime form but also contains three ic-4's which were to be excluded. Thus, there is no such hexachord.

- $\underline{[0,1,3, \cdot, \cdot, \cdot]:}$ : This automatically excludes pitch-classes $2,4,5,7,8,9, E$ which does not leave sufficiently many pitch-classes to complete the hexachord. (See Figure 11, Center.)

- $\underline{[0,2,3, \cdot, \cdot, \cdot]:}$ This automatically excludes pitch-classes $1,4,6,7,8, T, E$ which does not leave sufficiently many pitch-classes to complete the hexachord. (See Figure 11, Right.) 

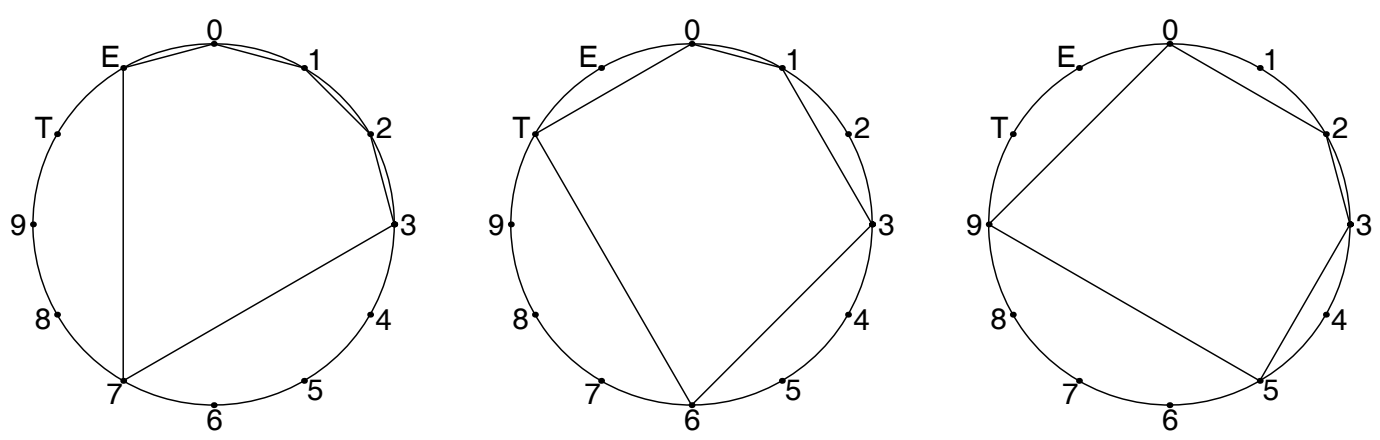

Figure 11: Excluding Major Thirds

- ic-5: $M_{7}$, the circle-of-fifths transformation, exchanges ic-1 and ic-5 while leaving all other interval-classes invariant [6, p. 104]. Thus, any hexachord excluding ic-5 and possessing the GUIM Property is the $M_{7}$ transform of a hexachord which excludes ic-1 and has the GUIM Property. But, it has already been shown that no such hexachord exists.

- $\underline{\text { ic-6: }}$ : See Figure 12.

- $[0,1,2, \cdot, \cdot, \cdot]:$ This automatically excludes pitch-classes $6,7,8$. Choosing $9, T$ or $E$ as the last pitch-class would require the inclusion of at least ic-4 in order to skip $6,7,8$. However, prime form would then require at least ic- 4 at the end of the chord which would preclude the inclusion of $9, T$ or $E$ which is a contradiction! Hence, the last pitch-class must be $\leq 5$ with 5 being the only choice leading to a hexachord. Thus, we are ultimately led to the only possible such hexachord, shown in the top frame of Figure 12, which is the chromatic hexachord $[0,1,2,3,4,5]$ whose interval vector is $\langle 5,4,3,2,1,0\rangle$. This does indeed possess the GUIM Property.

$-\underline{[0,1,3, \cdot, \cdot, \cdot]:}$ This automatically excludes pitch-classes $2,6,7,9$. A choice of $T$ or $E$ as the last pitch-class would require the inclusion of at least ic-3 in order to skip 6, 7. However, prime form would then require at least ic-3 at the end of the chord which would preclude the inclusion of $T$ or $E$ which is a contradiction! Hence, the last pitch-class must be $\leq 8$ with 8 being the only choice leading to a hexachord. Thus, we are ultimately led to the only possible such hexachord, shown in the middle-left frame of Figure 12, which is $[0,1,3,4,5,8]$ whose interval vector is $\langle 3,2,3,4,3,0\rangle$. This clearly does not possess the GUIM Property. 

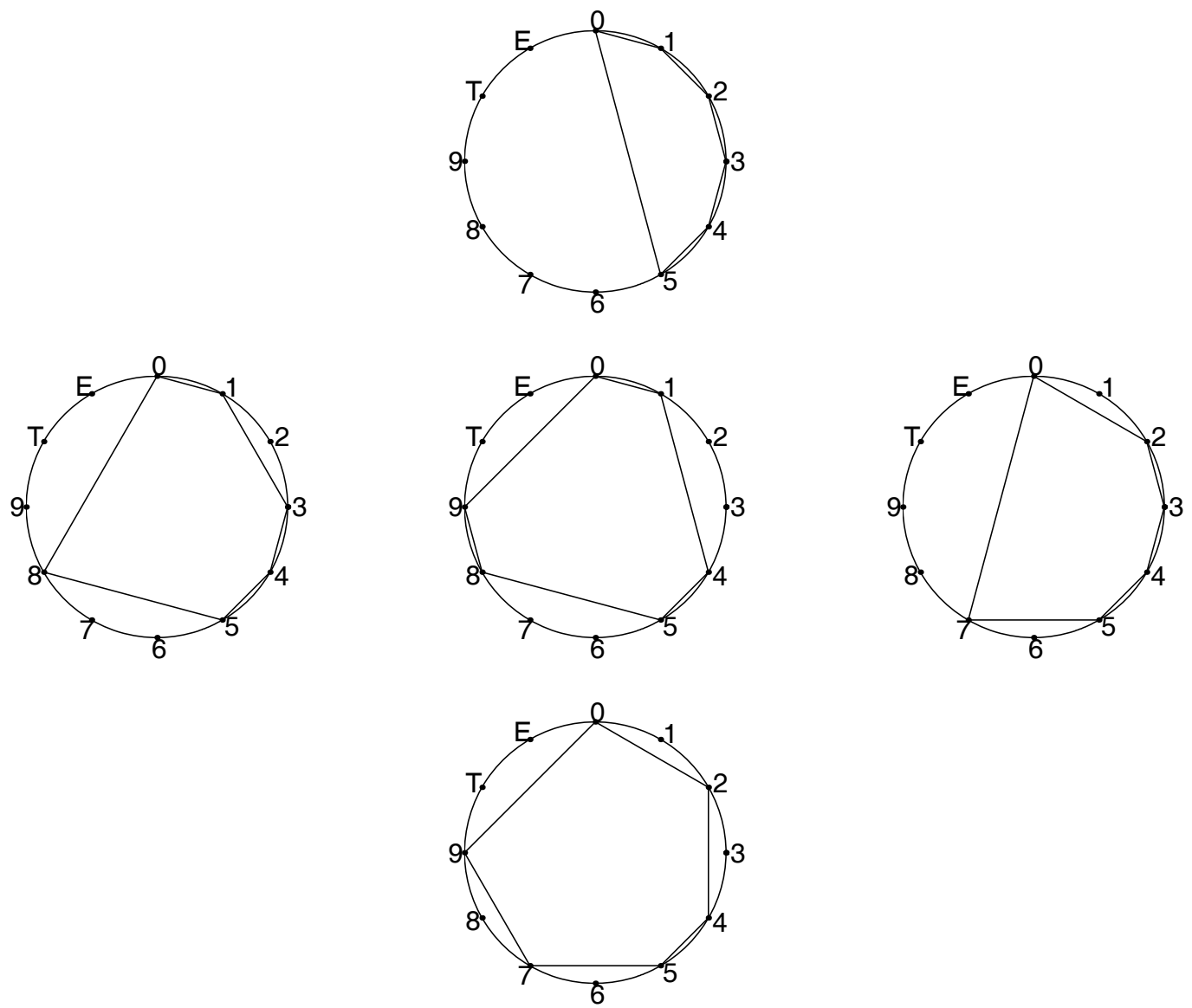

Figure 12: Excluding Tritones

- $[0,1,4, \cdot, \cdot, \cdot]:$ This automatically excludes pitch-classes $2,3,6,7, T$. The presence of edge 1-4 implies that, in order for the chord to be in prime form, the final interval-class must be at least ic-3. But, a final interval-class larger than ic-3 could not accommodate a hexachord so that the last pitch-class must be 9 . Thus, we are immediately led to the only possible such hexachord, shown in the middle-center frame of Figure 12, which is $[0,1,4,5,8,9]$ whose interval vector is $\langle 3,0,3,6,3,0\rangle$. This clearly does not possess the GUIM Property.

- $[0,2,3, \cdot, \cdot, \cdot]$ : This automatically excludes pitch-classes $1,6,8,9$. In order to be in prime form, the final interval-class must be at least ic-2. But a choice of $T$ as the last pitch-class would require a penultimate interval-class of at least ic-3 in order to skip over 8,9 and this would, in turn, violate the conditions for prime form. The only remaining choice for final pitch-class which accommodates a hexachord is 7 . Thus, we are immediately led to the only possible such 
hexachord, shown in the middle-right frame of Figure 12, which is $[0,2,3,4,5,7]$ whose interval vector is $\langle 3,4,3,2,3,0\rangle$. This clearly does not possess the GUIM Property.

- $[0,2,4, \cdot, \cdot, \cdot]$ : This automatically excludes pitch-classes $1,3,6,8, T$. In order to be in prime form, the final interval-class must be at least ic-2. But, since $T$ has been excluded, this final interval-class must be at least ic-3. The only remaining choice for final pitch-class which accommodates a hexachord is 9 . Thus, we are immediately led to the only possible such hexachord, shown in the bottom frame of Figure 12, which is the diatonic hexachord $[0,2,4,5,7,9]$ whose interval vector is $\langle 1,4,3,2,5,0\rangle$. This does indeed possess the GUIM Property.

Since the chromatic and diatonic hexachords are $M_{7}$ transforms of one another, up to rotation, reflection and circle-of fifths transformation, only the diatonic hexachord possesses the GUIM Property but not the UIM Property. The UIM Theorem thereby implies the GUIM Theorem.

\section{Coda}

Up to rotation, there are 351 different chords [3, p. 41] while, up to rotation and reflection, there are precisely 223 distinct set classes (equivalence classes of pc-sets) in the twelve-tone equal-tempered musical universe (1 unichord/hendecachord, 6 dichords/decachords, 12 trichords/nonachords, 29 tetrachords/octachords, 38 pentachords/septachords, 50 hexachords and 1 dodecachord). Hence, a brute force examination of their 223 interval vectors would yield a direct proof of the main theorem of this paper. (Lists of these interval vectors have been compiled in [6] and [7].) Not only would such an approach be mathematically grotesque, it would provide absolutely no insight into precisely what features of musical chords lead to the unique status of the diatonic hexachord and septachord as regards the GUIM Property. A much more mathematically satisfying approach is the geometric one adopted throughout this paper which requires the inspection of only 12 interval vectors.

The diatonic hexachord, which has played a central role in the foregoing deliberations, has also been of considerable import in the development of the Western Musical tradition. First introduced by Guido d'Arezzo in the 11th Century as a system of solmization [2], it blossomed into the medieval hexachord system before eventually yielding to the modern diatonic scale in the 17th Century [1].

Just as the Unique Intervallic Multiplicity Theorem, in combination with the Common Tones Theorem ([6, p. 107] and [7, p. 59]), implies that diatonic tonal music possesses the maximum degree of hierarchization of close- 


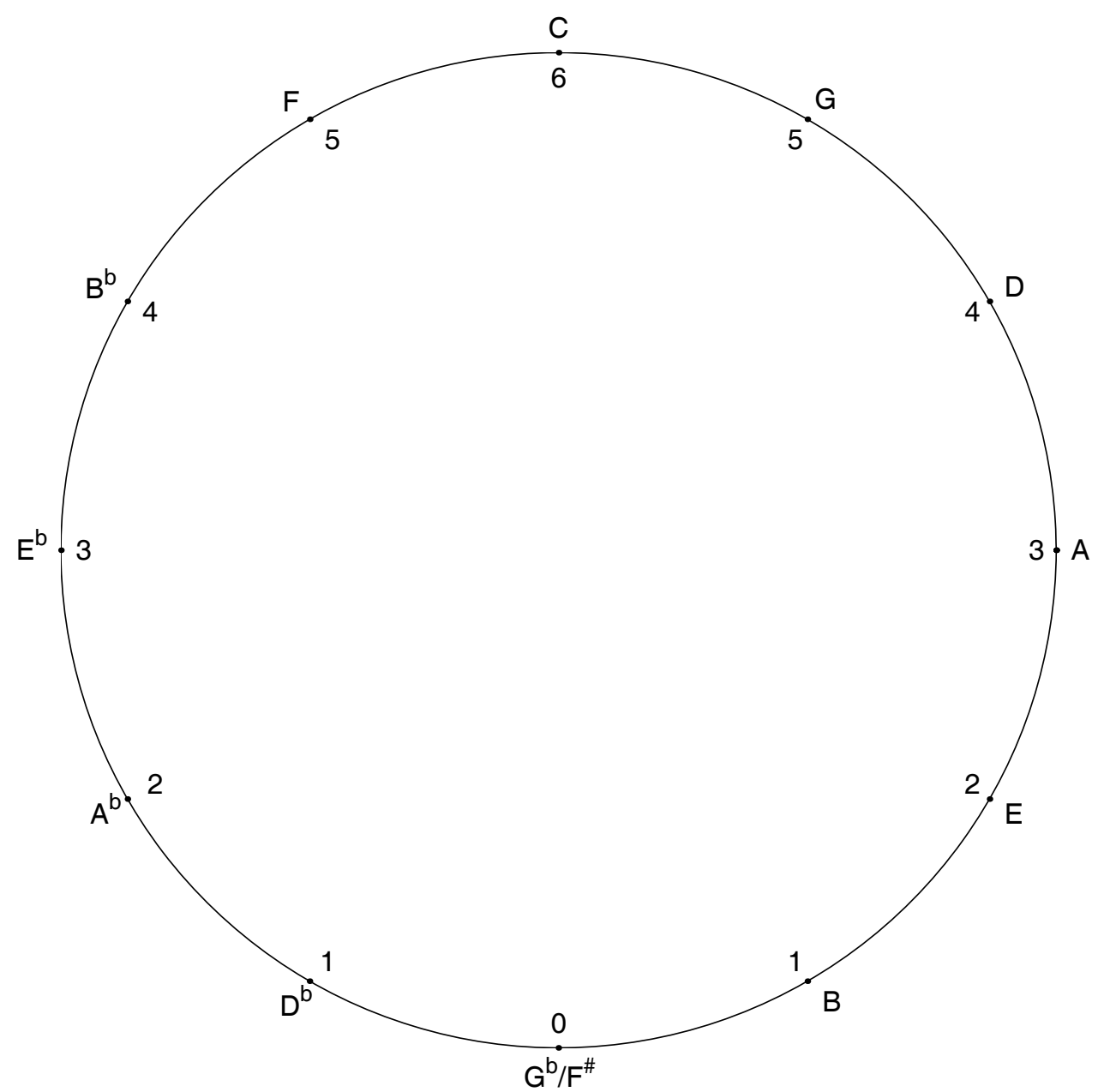

Figure 13: Degree of Relatedness

ness/remoteness amongst the twelve diatonic musical keys [4], the Generalized Unique Intervallic Multiplicity Theorem explored herein implies a similar maximal hierarchization amongst the twelve transpositions of the diatonic hexachord. This is illustrated in Figure 13 where these transpositions are arranged in a circle-of-fifths configuration with the interior numerical labels indicating the number of common tones which each diatonic hexachord shares with that having tonic $C$.

\section{Acknowledgement}

The author expresses heartfelt thanks to Mrs. Barbara McCartin for her invaluable assistance in the production of this paper. 


\section{References}

[1] Willi Apel, Harvard Dictionary of Music, Second Edition, Revised and Enlarged, Belknap Press, 1972.

[2] Donald J. Grout and Claude V. Palisca, A History of Western Music, Fourth Edition, Norton, 1988.

[3] Michael Keith, From Polychords to Polya: Adventures in Musical Combinatorics, Vinculum, 1991.

[4] Brian J. McCartin, "Prelude to Musical Geometry", College Mathematics Journal, Vol. 29, No. 5, November 1998, pp. 354-370.

[5] Brian J. McCartin, "A Geometric Demonstration of the Unique Intervallic Multiplicity Property of the Diatonic Musical Scale", International Mathematical Forum, Vol. 7, No. 57, 2012, pp. 2815-2825.

[6] John Rahn, Basic Atonal Theory, Schirmer, 1980.

[7] Joseph N. Straus, Introduction to Post-Tonal Theory, Prentice-Hall, 1990.

Received: April 1, 2014 